
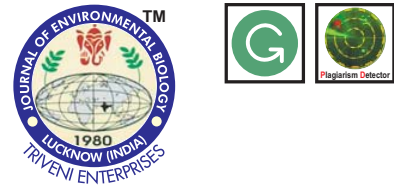

DOI : http://doi.org/10.22438/jeb/38/6(SI)/05

ISSN: 0254-8704 (Print) ISSN: 2394-0379 (Online) CODEN: JEBIDP

\title{
Phenology of three anuran species in Sierra de Guadalupe forest, Mexico
}

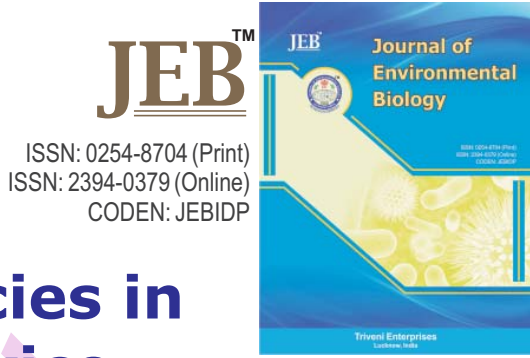

\section{Slerra de Guadalupe forest, Mexico}

\section{Authors Info}

S.F. Arias-Balderas ${ }^{1,2 *}$ and F.R. Méndez de la Cruz ${ }^{2 *}$

'Posgrado en Ciencias Biológicas, Universidad Nacional Autónoma de México, Circuito Exterior S/N, Ciudad Universitaria, Delegación Coyoacán, Mexico City, 04510, Mexico

${ }^{2}$ Zoology Department, Biology Institute, Universidad Nacional Autónoma de México, Circuito Exterior S/N, Ciudad Universitaria, Delegación Coyoacán, Mexico City, 04510, Mexico

${ }^{*}$ Corresponding Author Email : biolsarias@gmail.com

Key words

Amphibians

Behaviour

Environmental variables

Larval cycle

Publication Info

Paper received: 05.05.2016

Revised received : 07.12 .2016

Re-revised received: 18.01 .2017

Accepted : 24.02.2017

\section{Abstract}

Aim: Biological and ecological aspects of a large part of the Mexican anuran species are largely unknown. Information about their habits is helpful to establish the role they play in their environment. Hyla arenicolor, Spea multiplicata and Hyla eximia are widely distributed species and apparently coexist in much of the Mexican Altiplane. However, their reproductive strategies are different. The aim of this work was to determine the spatio-temporal distribution of these three species under field conditions.

Methodology: The populations of three species of anurans were studied in two ponds and one reservoir for five years from a Protected Natural Area, called the Sierra de Guadalupe (State of Mexico). Species presence, date, sex, age group, as well as air and water temperatures were recorded at sites, while the relative humidity and precipitation data were obtained from the Atmospheric Monitoring System of the City of Mexico. Analysis of variance (ANOVA) and circular statistics was carried out to determine the differences among species in presence, activity, and time in larval development.

Results: In all 1328 records of the three species were obtained. For the spatialtemporal distribution patterns, the results did not show significant differences in the occupation of the ponds. The species showed the peak activity from 17:00 to 00:00, with $H$. arenicolor being the only one that presented a bimodal activity. The sex ratio showed significant differences among the species. The highest similarities in sex ratio were found between $S$. multiplicata and $H$. arenicolor throughout the study, whereas $H$. eximia differed every year.

Interpretation: The implication of climatic factors showed that the years with the longest delay in the rainfall had influence on the presence of anurans and duration of permanency. This can accelerate the larval period of $S$. multiplicata. The shortening of reproductive phase and the life cycle from tadpole to adult can have adverse effects on the anuran population.

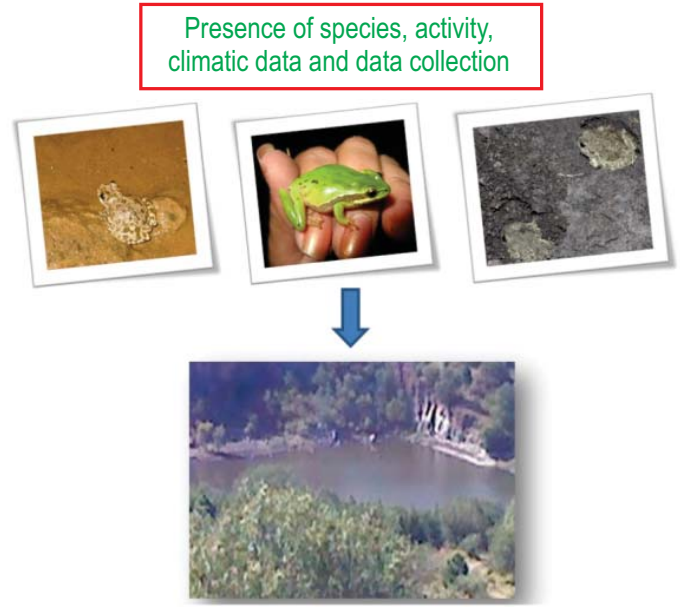

Protected natural area "Sierra de Guadalupe"

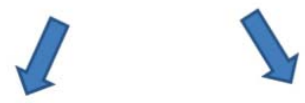

Yearly changes in presence, sex ratio and larval development each specie

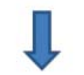

Data analysis 


\section{Introduction}

Local distribution of many amphibians is limited by the restrictions demanded by the reproduction mode (Cushman, 2006). Evidently, aquatic larval forms are part of these restrictions because they require adequate lapses of hydroperiod that may be variable each year (Skelly et al., 1999). Anurans, the order to which study species belong, spend the first part of their lives as aquatic herbivores (or in some cases as omnivores) and the latter part as terrestrial carnivores. The larval stage is only devoted to growth, while adulthood is for reproduction, dispersion and survival under different climatic conditions (Wilbur, 1980).

It has been observed that many temperate amphibians migrate each year to ponds for breeding and rearing. Often the temperate and Mediterranean environments present a short period for reproduction (Salvador and Carrascal, 1990). The beginning and duration of this period is influenced by diverse factors such as precipitation and temperature (Salthe and Mecham, 1974; Semlitsch, 1985), as well as by biotic factors, such as intra and interspecific competition (Wilbur, 1980; Crump, 1982) which often act in complex ways affecting the survival, larval development, and metamorphosis (Brockelman, 1969; Wilbur and Collins, 1973; DeBenedictis, 1974; Wilbur, 1987).

Because many species of amphibians often breed in the same pond, some of them use the temporal segregation strategy to avoid competition and predation pressure (Blair, 1961; Wilbur, $1980,1987)$. Species divide the aquatic habitat into space or time for mating, breeding and larval development by adjusting time according to these conditions and to existing resources (Wilbur, 1980).

Conditions in aquatic habitats strongly influence the duration of the larval phase of amphibian species, which may last for weeks or even years depending on the species (Werner, 1986, Alford and Harris, 1988). Although time and size in metamorphosis are flexible life history traits, the minimum and maximum duration in this period are species-specific (Wilbur and Collins, 1973, Smith, 1987, Alford and Harris, 1988). In unvafourable or short-lived aquatic environments, larvae rapidly transform and become small in size due to rapid drying of ponds and high levels of competition or predation. However, under favourable conditions, larvae may prolong metamorphosis and become larger (Alford, 1999).

Hyla arenicolor, Hyla eximia and Spea multiplicata are distributed in USA and Mexico from North of Chihuahua and Tamaulipas until North of Oaxaca, Mexico. They are often encountered in the rainy season in temperate forest areas; however, they usually emerge at different times. Most larval ecology of amphibians can be generalized in a gradient, with species well established to coexist, with predators and competitors in the temporary pools. Thus, abiotic factors (such as hydroperiod) and biotic factors (such as interactions) work in a complex cost-benefit system that influences larval ability and the success of metamorphosis (Woodward 1982, 1983, Skelly 1995, McDiarmid and Altig 1999). Therefore determining the spatio-temporal distribution of these three species is important to distinguish the requirements of each of them. In addition, the present work examines the possible influence of environmental factors such as temperature, precipitation and humidity at the beginning and at the end of reproduction and the limits that determine the presence (or absence) of a given species.

\section{Materials and Methods}

The populations of three species of anurans, Hyla arenicolor, $H$. eximia and Spea multiplicata were studied in two ponds and a reservoir from May 2008 to November 2012. The study area is about $70 \mathrm{~km}^{2}$ and belongs to the Protected Natural Area "Sierra de Guadalupe" located in the State of Mexico. Plant species, Quercus deserticola, Q. rugose, Acacia farnesiana, Buddleia americana, Bursera sp., Cilindropuntia imbricata, Opuntia lasiacantha and O. streptacantha inhabit the study area. The ponds are surrounded by oak forest and xerophytic scrubs and with less than $1 \mathrm{~km}$ distance between them. One of the ponds has an almost permanent hydroperiod, while the others dry mostly during winter and spring. Species presence, date, sex, age group, as well as air and water temperatures were recorded at sites, while relative humidity and precipitation data were compiled from the Atmospheric Monitoring System of the City of Mexico, in order to be able to compare the changes that could present the species between the years of study.

Once the data were obtained by year and month of each species, as well as the environmental variables (temperature, humidity and precipitation), we analyzed the annual presence of each one, the distribution in space-time, sex ratio and the period of larval development until the metamorphosis through periodic records in the study area. Analysis of variance (ANOVA) was carried out to determine if there were differences between species with respect to the time of larval development.

Circular statistics were used to determine the activity schedule of each species using the Watson (Batschelet, 1981) paired comparison test and the Kuiper K test, in order to establish if the activity schedules behave in a uniform way or there were differences among species (Salgado-Ugarte et al., 1993; 1995; 2009; 2011).

We compared the value of $U^{2}$ calculated with the critical values of tables for Watson's $U^{2}$. If the calculated value is higher than the tables, we reject the null hypothesis, in this case the uniformity in the activity schedule of the species and in the Kuiper's K case applies similarly showing differences when the calculated $\mathrm{K}$ is greater than that of tables (Batschelet, 1981). 


\section{Results and Discussion}

A total of 1328 records of the three species, counting metamorphs (young) and adults were obtained, with being $S$. multiplicata the one with the highest number (1060), followed by Hyla arenicolor with 180 records and the least abundant was $H$. eximia with 88 records. Regarding the spatial-temporal distribution, the results did not show significant $(P=0.594)$ differences in the occupation of the ponds, since these were occupied indiscriminately by the three species. However, it was evident that these were linked to the first constant rains. Thus, from 2008 to 2010 they were favoured by the presence and duration of the three species, while in 2011 and 2012 the period of permanence of the species was much lower. During $2011 \mathrm{H}$. arenicolor remained only for two months unlike the four to five months that were present in the other years. $H$. eximia was present for two months each year (Fig. 2) but its abundance was reduced, being limited to only seven records in 2011 and 2012 (three and four records, respectively). The species showed a peak activity from 17:00 to 00:00, with $\mathrm{H}$. arenicolor being the only one that presented a bimodal activity, from 09:00 to 12:00 and from 17:00 to 00:00h while $S$. multiplicata showed activity from 18:00-22:00h and H. eximia from 19:00-00:00h (Fig. 3). The sex ratio also showed significant differences among the species (ANOVA, $\mathrm{P}=0.008$ ), and for $\mathrm{H}$. eximia and $\mathrm{S}$. multiplicata the tstudent test showed differences between the sexes $(P=0.047$ and $\mathrm{P}=<0.001$ ) (Fig. 4).

Another difference among the studied species was that the sex ratio changed each year of study. The highest similarities in sex ratio were found between $S$. multiplicata and $H$. arenicolor throughout the study, whereas $\mathrm{H}$. eximia differed every year because of a higher number of males, and even without females in 2010, 25\% in 2011 and 29\% in 2012. Evidently, the effects of the delay of rainfall occurred in the first two years mentioned (Fig.4).

The larval development was also linked to the annual rainfall regime and the presence of humidity, emphasizing that in the years with less rainfall the larval development was accelerated in S. multiplicata, whereas for the rest of the species this did not alter the time of development (Fig. 5).

Amphibians should restrict their activity time during the day when optimal conditions are present and their performance is optimum (Duellman and Trueb, 1985; Donelly and Crump, 1998). Temperature and humidity are fundamental to these activities (Pounds, 2001; Pounds, 2006). For example, in tropical regions some amphibians may be active practically all day (Donelly and Crump, 1998). However, in cold regions the schedules are much more restricted, although some may be active at practically freezing temperatures. In temperate regions amphibians are restricted to the spring and summer seasons, when favourable temperatures and summer rains occur, as is the case with most amphibians inhabiting the semi-arid zones of Mexico (Buchholz and Hayes, 2000). This case is represented in this work with all the studied species, where the presence is evident during the summer rains.

One of the fundamental questions is whether the organisms present their activity according to the phylogenetic inertia or by a total influence of the environment in which they inhabit (Buckley and Jetz, 2007). Hyla arenicolor and H. eximia are closer phylogenetically, while $S$. multiplicata belongs to a different family (Pyron and Wiens, 2011). However, the activity of the three species studied showed certain similarities. The spatial distribution of species was also similar because pond conditions gave them shelters, such as rocks and plants as well as providing with abundant prey (crustaceans such as cladocerans). Abiotic factors such as depth $(50-150 \mathrm{~cm})$ and pH (7-7.5) also favoured the reproduction of these species. The results indicate that a suitable environment for the species under study included small and isolated water bodies with submerged vegetation, as proposed for other amphibians (Conner et al., 2008).

As for the species' temporality, the presence of the three species was defined by the first rains and the presence of humidity in the environment. The data obtained during the present study agree with that reported by McMenamin et al. (2008), where the climate impacts have adversely affected the presence of populations of some amphibian species in Yellowstone National Park and have caused their population decline. In addition, in the present study it was observed that the three species restricted their presence in the years where rainfall and humidity were minor or late (Fig. 2). Likewise, no obvious effects were observed with the delay in the rainfall regimen in terms of abundance, as noted for $H$. arenicolor and S. multiplicata (Beebe, 1995). However, $H$. eximia seems to be more sensitive, since it emerges when the pool has a depth $>50 \mathrm{~cm}$. The effect of delays in the rainfall regime

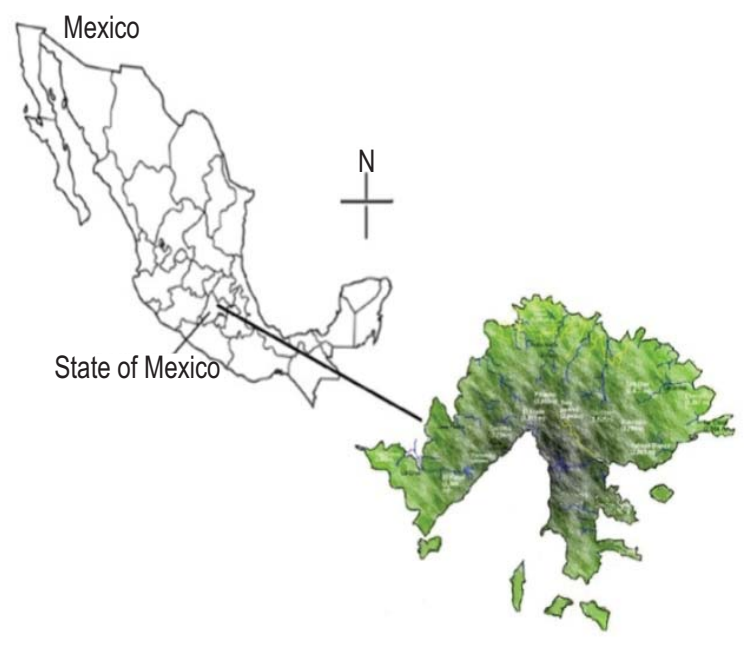

Fig. 1 : Map of Sierra de Guadalupe, México 

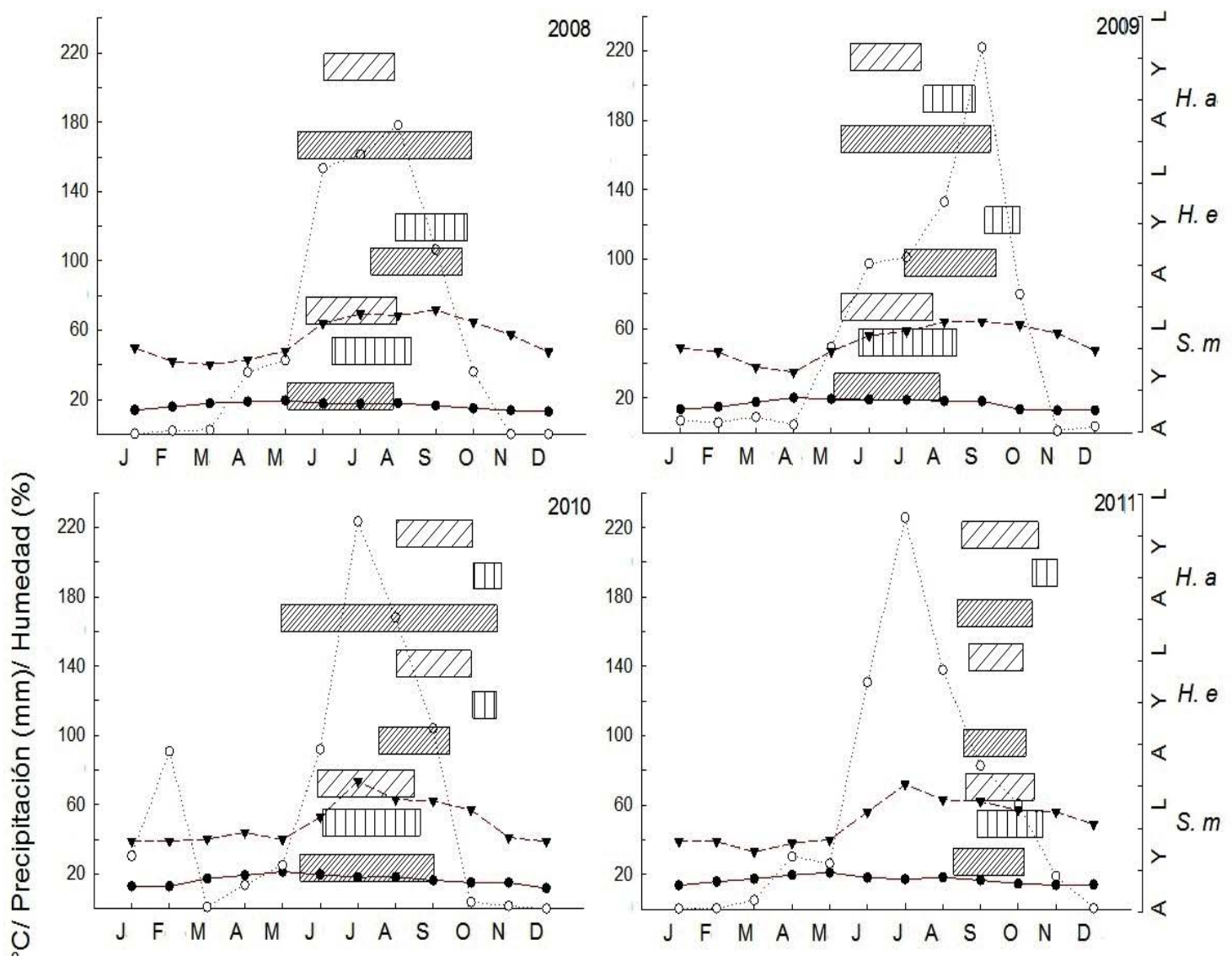

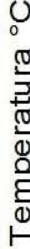

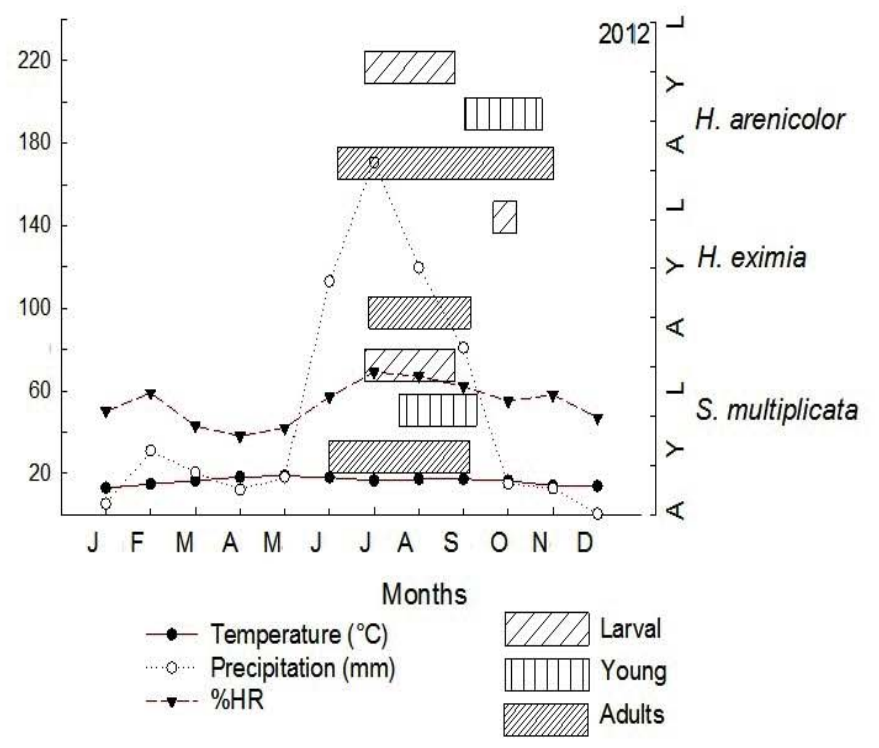

Fig. 2 : Variation in climatic variables (temperature, precipitation and relative humidity) related with anuran presence during 2008-2012 


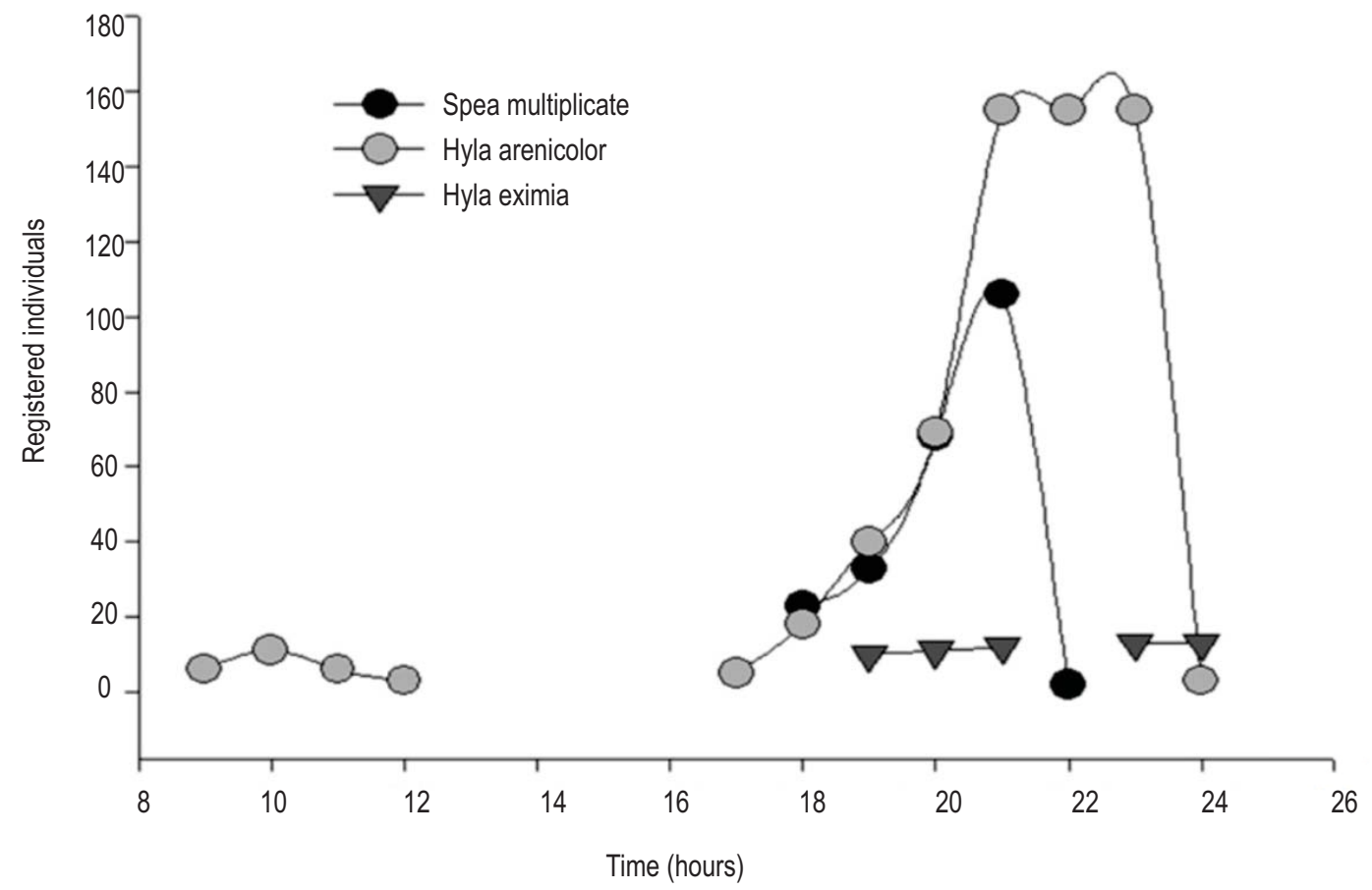

Fig. 3 : Activity in three species along day

2008

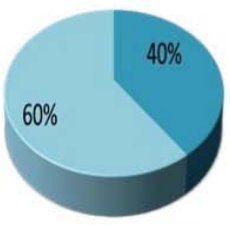

Males Females

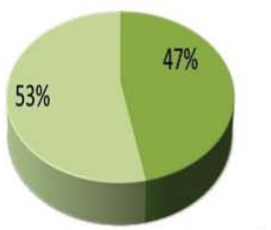

Males Females

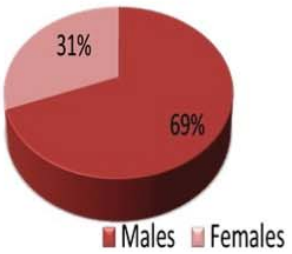

2009
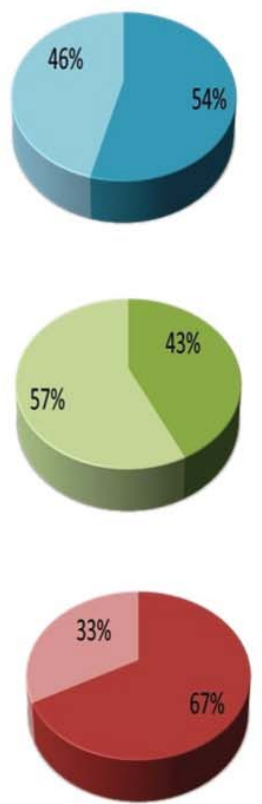

2010
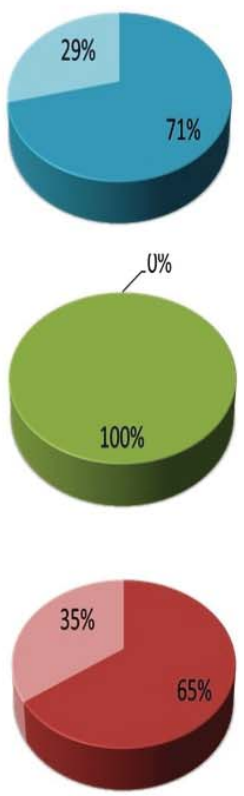

2011

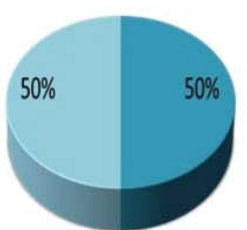

$25 \%$
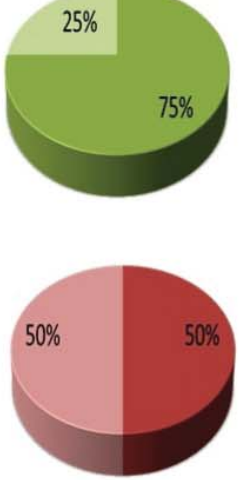

2012

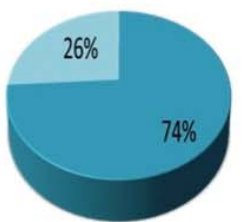

H. a

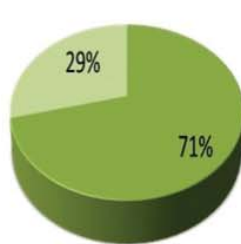

H. e

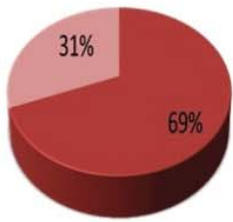

S. $m$

Fig. 4 : Yearly variations in the sex ratio in three anuran species 2008-2012, where Hyla arenicolor=H.a, Hyla eximia = H. e and Spe amultiplicata= S.m. 


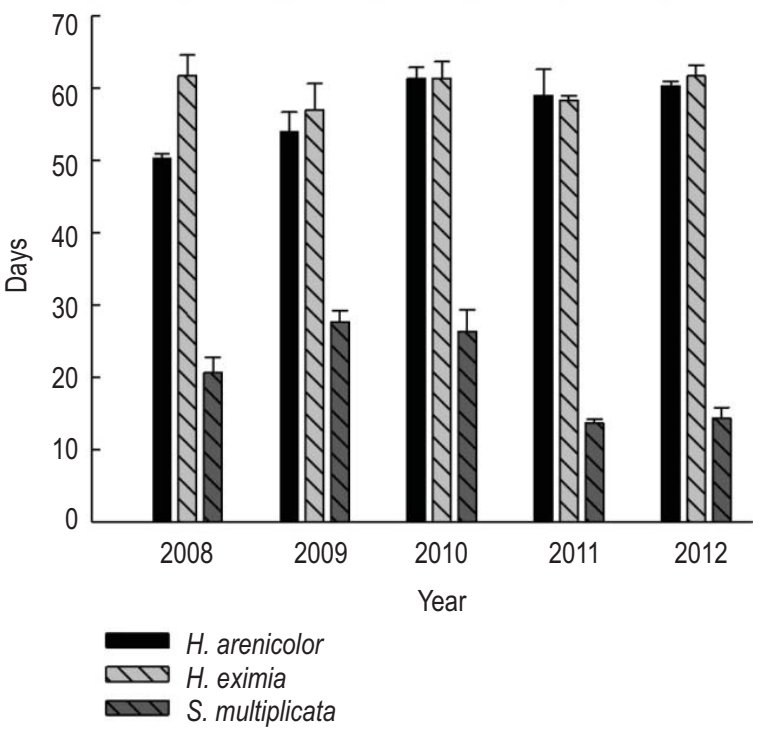

Fig. 5 : Time in larval development each year during 2008-2012. Values present mean \pm standard error

was evidenced by the marked decline of organisms in subsequent years (Fig. 2 and 4).

The daily activity among studied species was delayed maximum an hour. However, the only one that recorded two peaks of activity was $\mathrm{H}$. arenicolor, that also shows crepuscular or nocturnal habits even though found active during the day. A group of anurans, such as $H$. arenicolor, have tubercles on the skin which secrete a lipid substance that prevents desiccation and this helps them tolerate solar radiation in adulthood (Hillman et al., 2009).

The causes of declining species of a large number of anurans have been focussed on diseases provocated by loss of biodiversity, deforestation, introduction of exotic species, pesticides, etc. (Carey et al., 2003). However, adverse factors affecting sex ratio have been poorly documented. The present study shows that due to the effect on rainfall regimes, this can lead to fatal consequences for the stability of amphibians, as documented earlier (Alexander and Eischeid, 2001; Cushman, 2006). H. eximia seems to suffer serious consequences because the alteration in the rainfall regime had a significant effect on the sex ratio during 2010 and the subsequentyears only showed a slight recovery.

The larval development time in amphibians is highly variable; it can last from a few days to three years as has been observed in some species of Ascaphus and Rana. It has also been recorded that some species may delay or accelerate this process depending on the degree of predation in the ponds or the drying time of the waterbodies (Denver, et al., 1998). For the species studied here, the development time was similar during the years of study, where a more similar pattern was registered between $H$. arenicolor and $H$. eximia, with a period close to 60 days. S. multiplicata showed plasticity in larval development time, since in favourable years the development extended from one to two months, and in years with delayed rains, the duration in the larval development accelerated to only 15 days. This seems to be an opportunistic behaviour depending on the food availability, temperature (Buchholz, 2000) and even the temporality of the ponds.

The strategies used by the anurans in terms of the opportunities offered by ponds for reproduction and larval development are well documented. These strategies have also been recorded in anurans with aquatic eggs where the characteristics of ponds coupled with abiotic factors such as temperature, humidity and rainfall can alter the biological cycles of these species. As observed here, the rainy season itself can cause a decline in the abundance of the species. In the years with a greater delay in the rains the presence of the three species was altered, although the most affected was $H$. eximia. However, it seems that the phylogenetic constraints that exist between $H$. arenicolor and $S$. multiplicata neither interfere in the preference of the activity times, nor in the sex ratio since these were similar. On the other hand, $H$. arenicolor and $H$. eximia appear to retain these phylogenetic affinities in relation to larval development, whereas S. multiplicata was the one that showed the greatest plasticity and seems to be the least susceptible to changes in rainfall. H. eximia, on the other hand, proved to be the most sensitive to the limit of putting at risk the sex ratio that could potentially lead to the extinction of the population.

\section{Acknowledgments}

The first author declares this paper is a requirement to obtain the PhD in Sciences from the program of Posgrado en Ciencias Biológicas, UNAM. She thanks the Posgrado en Ciencias Biológicas, Universidad Nacional Autónoma de México and CONACYT for scholarship funding (CVU 294891).Thanks are due to Dr. Salgado-Ugarte for the help with the circular statistics. Elisa Pamela Mendoza Argueta, Rafael Alejandro Calzada Arciniega and Raúl Gómez Trejo Pérez helped in the field work. FRM thanks the Macrosystems Project (NSF) and PAPIIT-UNAM IN210116.

\section{References}

Alexander, M.A. and J.K. Eischeid: Climate variability in regions of amphibian declines. Conservation Biology, 15, 930-942.(2001).

Alford, R.A.: Ecology: resource use, competition and predation, In: Tadpoles: The Biology of Anuran Larvae (Eds.: Roy. W.Mc Diarmid and R. Altig). The University of Chicago Press, Chicago. pp. 189214.(1999)

Alford, R.A. and R.N. Harris: Effects of larval growth history on anuran 
metamorphosis. American Naturalist, 131, 91-106 (1988).

Beebee, T.J.C.: Amphibian breeding and climate. Nature, 374, 219-220 (1995).

Blair, W.F.: Calling and spawning seasons in a mixed population of anurans. Ecology, 42, 99-110 (1961).

Brockelman, W.Y.: An analysis of density effects and predation in Bufo americanus tadpoles. Ecology, 50, 632-644.(1969).

Buchholz, D.R. and T.B. Hayes: Larval period comparison for the Spadefoot toads Scaphiopus couchii and Spea multiplicata (Pelobatidae:Anura). Herpetologica, 4, 455-468.(2000).

Buckley, L.B. and W. Jetz: Environmental and historical constraints on global patterns of amphibian richness. Proceedings of the Royal Society B, 274, 1167-1173 (2007).

Carey, C., D.F. Bradford, J.L. Brunner, J.P. Collins, E.W. Davidson, J.E. Longcore, M. Ouellet, A.P. Pessier and D.M. Schock: Biotic factors in amphibian population declines. In: Amphibian decline: An integrated analysis of multiple stressor effects (Eds.: G. Linder, S.K. Krest and D.W. Sparling). Society of Environmental Toxicology and Chemistry, Pensacola, Florida, pp. 153-208 (2003).

Conner, C.A., E.B. Harper and R.D. Semlitsch: Breeding and recruitment phenology of amphibians in Missouri Oak-Hickory Forests. American Midland Naturalist, 160, 41-60 (2008).

Cushman, S.A.: Effects of habitat loss and fragmentation on amphibians: A review and prospectus. Biological Conservation,128, 231-240 (2006).

Crump, M.L.:Amphibian reproductive ecology on the community ecology level. In : Herpetological communities (Ed.: N.J. Scott). U.S. Fish Wild. Service, Wild. Res. Rep. 13, pp. 21-36 (1982).

Denver, R.J., M. Nooshan and M. Phillips: Adaptive plasticity in amphibian metamorphosis: Response of Scaphiopus hammondii tadpoles to habitat desiccation. Ecology, 79, 1859-1872(1998).

Donelly, M.A. and M.L. Crump: Potential effects of climate change on two neotropical amphibian assemblages. Climatic Change, 39, $541-$ 561 (1998).

Duellman, W.E. and L. Trueb: Biology of amphibians. McGraw-Hill Book Company. Toronto (1986).

Hillman, S.S., P.C. Withers, R.C. Drewes and S.D. Hillyard: Ecological and Environmental Physiology of Amphibians, Oxford University Press. E.U.A., p. 469 (2009).

McDiarmid, R.W. and R. Altig: Tadpoles the biology of anuran larvae.
University of Chicago Press, p. 444 (1999).

Pounds, J.A.: Climate and amphibian declines. Nature, 410, 639640.(2001).

Pounds, J.A.: Widespread amphibian declines from epidemic disease driven for global warning. Nature, 439, 161-167 (2006).

Pyron, R.A. and J.J. Wiens: A large-scale phylogeny of Amphibia including over 2800 species, and a revised classification of extant frogs, salamanders, and caecilians. Mol. Phylogen. Evol., 61, 543-583.(2011).

Salthe, S.N. and J.S. Mecham: Reproductive and courtship patterns. In: Physiology of the Amphibia (Ed.: B. Lofts). Academic Press, New York, pp. 309-521(1974).

Salvador, A. and L.M. Carrascal: Reproductive phenology and temporal patterns of mate access in mediterranean anurans. J. Herpetol., 4, 438-441 (1990)

Semlitsch, R.D.: Analysis of climatic factors influencing migrations of the salamander Ambystoma talpoideum. Copeia, 1985, 477-489 (1985).

Skelly, D.K.A.: Behavioral trade-off and its consequences for the distribution of Pseudacris treefrog larvae. Ecology, 76, 150-164 (1995).

Skelly, D.K., E.E. Werner and S.A. Cortwright: Long-term distributional dynamics of a Michigan amphibian assemblage. Ecology, 80, 2326-2337(1999).

Smith, D.C.: Adult recruitment in chorus frogs: Effects of size and date at metamorphosis. Ecology, 68, 344-350 (1987).

Werner, E.E.: Amphibian metamorphosis: Growth rate, predation risk and the optimal size at transformation. American Naturalist,128, 319-341 (1986)

Wilbur, H.M.: Complex life cycles. Ann. Rev. Ecol. Syst., 11, 67-93 (1980).

Wilbur, H.M.: Regulation of structure in complex systems: Experimental temporary pond communities. Ecology, 68, 1437-1452 (1987).

Wilbur, H.M. and J.P. Collins: Ecological aspects of amphibian metamorphosis. Science, 182, 1305-1314 (1973).

Woodward, B.D.: Tadpole competition in a desert anuran community. Oecologia, 54, 96-100 (1982).

Woodward, B.D.: Predator-prey interactions and breeding-pond use of temporary-pond species in a desert anuran community. Ecology, 64, 1549-1555(1983). 